Ann. Physiol. Anthrop.

13(3): 121-127, 1994.

\title{
Effects of Wearing Compression Stockings on Cardiovascular Responses
}

\author{
Shigeki Watanuki and Hiroko Murata \\ Faculty of Human Life Science, Osaka City University
}

\begin{abstract}
To investigate the effects of wearing compression stockings on cardiovascular responses, the heart rate $(\mathrm{HR})$, cardiac output $(\dot{\mathrm{Q}})$ measured by $\mathrm{CO}_{2}$ rebreathing method, and oxygen intake were measured at rest in a supine position for $40 \mathrm{~min}$ and standing position for $120 \mathrm{~min}$. Six female subjects wore the compression stockings after $20 \mathrm{~min}$ of rest at supine position. The oxygen intake and ventilation showed no significant difference between with and without the stockings. $\dot{Q}$ at standing position was lower than that at supine position by an act of hydrostatic pressure. However this decrease was lower with stockings than that without stockings. The compression stockings used in this study might improve the venous return to the heart. However, the subjects complained of discomfort due to the high clothing pressure. In the second experiment, the authors estimated the minimum pressure required in improving the venous return. The subjects wore the trousers having two bladders inflated by air pressure. The trousers could compress the leg (contain the foot) and thigh individually. From the relationship between air pressure and $\dot{Q}$, the estimated minimum pressures were $17 \mathrm{mmHg}$ for the leg and $15 \mathrm{mmHg}$ for the thigh.
\end{abstract}

(Ann. Physiol. Anthrop. 13(3): 121-127, 1994)

Key words : Compression stocking, Cardiac output, Heart rate, Posture, Pressure sensation

The erect bipedalism is a main characteristic of the human being. For this characteristic, man experiences the effects of the force of gravity, i.e. hydrostatic problems in the clearance of blood from the legs. To transport the blood in the legs to the heart, man has some physiological mechanisms, e.g. the venous valves, muscle pumps and negative pressure exerted by the diaphragm with each inspiration.

The blood shifts to the limbs if a man alters his posture from a supine to a standing position. Therefore, the hydrostatic pressure in the vein increases. Although accumulated blood may be transported by the hydrodynamic pressure (venous pressure minus hydrostatic pressure) produced by the mechanism as mentioned above, the cardiac output $(\dot{Q})$ is lower by the range from $20 \%$ to $30 \%$ in standing relative to the supine position for the decrease of venous return (e.g. Katsuura, 1979). So the heart rate (HR) increases for the insurance of the blood circulation.

On the other hand, the horizontal force of hydrostatic pressure in the capillaries may affect the wall of the capillaries. If the hydrostatic pressure is higher than interstitial fluid pressure around the capillaries, the fluid in the capillaries flow to the interstitial tissue. Accordingly the legs begin to swell. Prolonged standing position increases the physiological strain.

Recently, numerous advertisements on clothing aided with special functions have been seen on TV and in magazines. Compression stockings is one of them. The advertisement publicizes functions such as effective in improving the blood circulation and 
to inhibit the swelling. Even remarkably is that no report has been published on whether these effects occur during wearing the compression stockings. To provide comfortable stockings to the consumers, it is important for the consumers and textile manufacturers to know the true information, e.g. the relationship between compression rate and the venous return etc.

Although several researchers investigated the effects of wearing the compression garments on skin temperature and skin blood flow measured by Lazor Doppler, it is insufficient for these parameters to evaluate the venous return or venous pooling, i.e. the change of total blood circulation. Especially, compression stockings aim to improve the venous return against the gravity so that $\dot{Q}$ as an index of venous return or total blood circulation should be measured to evaluate the compression stockings.

The purpose of this study was to investigate the effects of wearing compression stockings on $\dot{Q}$ and to estimate the appropriate pressure for promoting the venous return during prolonged standing position.

\section{Method}

The environmental temperature and relative humidity in the test room were $24(23.7-25.6){ }^{\circ} \mathrm{C}$ and $54(52-58) \%$ respectively.

\section{Evaluation of compression stockings (EXP.1)}

The compression stockings (ready made, type: pantyhose with a cratch) used in this study has three sizes. The subjects wore one of them which fit their body sizes. The stockings has the following material characteristics: 212 denier, double covered yarn, tuck knit. The weight was $60.52 \mathrm{~g}$ (Middle size). The thickness of the stockings at the leg was $0.344 \mathrm{~mm}$.

The subjects were six young females (Table 1). They put on short pants and $\mathrm{T}$-shirts. The subjects stood up for 120 min after rest in a supine position for $40 \mathrm{~min}$. Forty minutes rest at supine position is needed for the stabilization of plasma volume by body posture change from standing position to
Table 1 Physical characteristics of subjects. Body fat percent (\%Fat) was calculated by the formula of Brožek et al. (1963). The body density was calculated by the formula of Nagamine and Suzuki (1964).

\begin{tabular}{|cccc|}
\hline Subject & Height $(\mathrm{cm})$ & Weight $(\mathrm{kg})$ & \%Fat \\
A & 153.0 & 45.0 & 24.6 \\
B & 160.0 & 47.3 & 25.1 \\
C & 162.1 & 57.5 & 27.1 \\
D & 161.4 & 49.8 & 23.2 \\
E & 162.2 & 51.3 & 23.5 \\
F & 155.3 & 48.7 & 25.1 \\
MEAN & 159.0 & 49.9 & 24.8 \\
S.D. & 3.9 & 4.3 & 1.4 \\
\hline
\end{tabular}

supine position (Hagan et al., 1978). The subjects set their arms on the stand (Fig. 1) and maintained their standing position with minimal movement (e.g., the shift of the center of gravity). They wore the compression stockings after $20 \mathrm{~min}$ of rest at supine position. During these conditions, HR with ECG leads (FUKUDA DENSI, FX-601), the oxygen consumption $\left(\dot{\mathrm{V}}_{2}\right)$ by Douglas bag method and $\dot{\mathrm{Q}}$ by $\mathrm{CO}_{2}$ rebreathing method were measured. The $\mathrm{O}_{2}$ and $\mathrm{CO}_{2}$ concentrations in the expired gas were analyzed by the gas analyzer (FUKUDA DENSHI, RE5000). The girth of the thigh (the middle point between patella center and iliospinale anterius) and leg (the middle point between sphyrion and patella center) were measured at the end of rest in supine and standing positions. The subjectively feelings, e.g. restriction, mobility, fatigue, and dullness during wearing the compression stockings were asked.

\section{Estimation of appropriate pressure for promot- ing the venous return (EXP. 2)}

The subjects wore trousers having two bladders inflated by air pressure. The trousers could compress the thigh and the leg (including the foot) separately (Fig. 1). The practical pressure applied to the skin by wearing the compression stockings was 


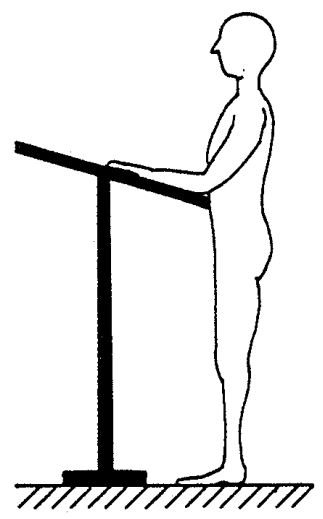

EXP. 1

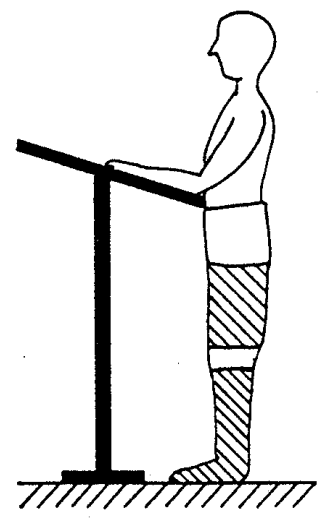

EXP. 2
Fig. 1 Diagram of the experiment 1 (left figure) and experiment 2 (right figure). In the right figure, the shaded parts show pressurized region.

$20 \mathrm{mmHg}$ at the thigh and $25 \mathrm{mmHg}$ at the leg (Measurements were carried out in Unitika Res. Lab. Inc.). Therefore, the applied pressure to the thigh and the leg in this experiment were set up

$* p<0.05, * * p<0.01$
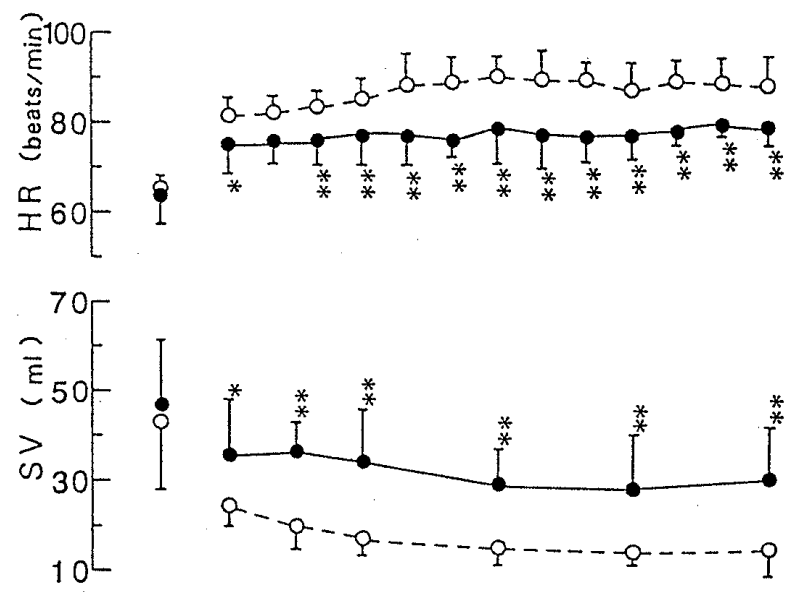

$\stackrel{.}{E}^{5.0}{ }_{1.0}^{5.0}[$

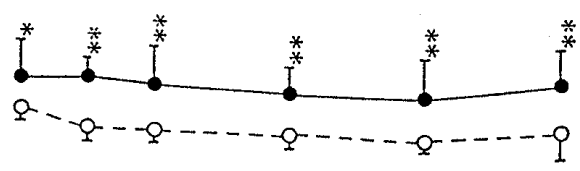

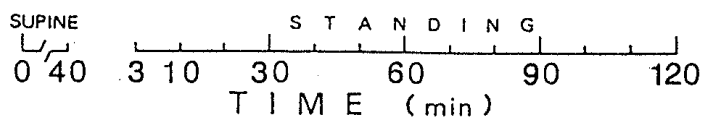

Fig. 2 The difference of heart rate (HR: mean SD), stroke volume (SV) and cardiac output ( $\dot{Q})$ between with $(O)$ and without $(O)$ the compression stocking during the supine and standing positions. following three kinds of combinations : 8 and 10,12 and 15,16 and $20 \mathrm{mmHg}$ respectively. The subjects and procedure were the same as EXP. 1.

\section{RESULTS}

\section{1) EXP. 1}

Figure 2 shows the difference of HR, stroke volume (SV) and $\dot{\mathrm{Q}}$ between with and without the compression stockings. There was no significant difference between the two conditions during the supine position. In standing position, however, $\dot{Q}$ and SV with the compression stockings was significantly larger than that of control (i.e. without compression stockings). HR with wearing the compression stockings was significantly lower than that of control.

Figure 3 shows the difference of pulmonary venti-
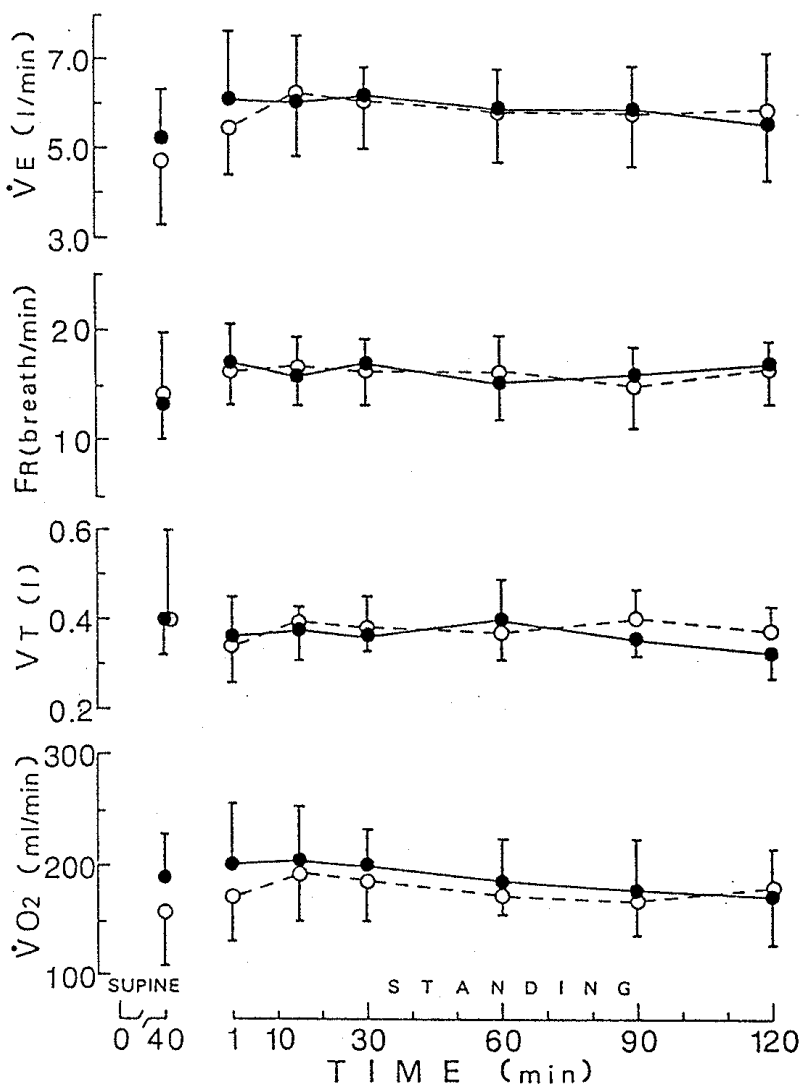

Fig. 3 The difference of pulmonary ventilation $\left(\dot{\mathrm{V}}_{\mathrm{E}}\right.$ : mean $\mathrm{SD})$, respiratory frequency $\left(\mathrm{F}_{\mathrm{R}}\right)$, tidal volume $\left(\mathrm{V}_{\mathrm{T}}\right)$ and oxygen intake $\left(\mathrm{V}_{2}\right)$ between with (O)and without $(\bigcirc)$ the compression stockings during the supine and standing positions. 
lation, respiratory frequency, tidal volume and $\dot{\mathrm{V}}_{2}$ between the two conditions. Significant difference was not shown between the two conditions in both supine and standing positions in each parameter.

Figure 4 shows the relationship between the thigh girth and HR. The plotted data were shown by subtracting the value at the end of supine position from that at the end of standing. Notice should be given that the girth (O) at the end of standing with the compression stockings was shorter than that at the end of supine position without it, whereas the girth $(O)$ at control was increased by standing. This difference is remarkable. It shows that the compression rate may be somewhat large. Furthermore, the subjects might have reported uncomfortable subjective feelings by wearing the compression stocking (Fig. 5).

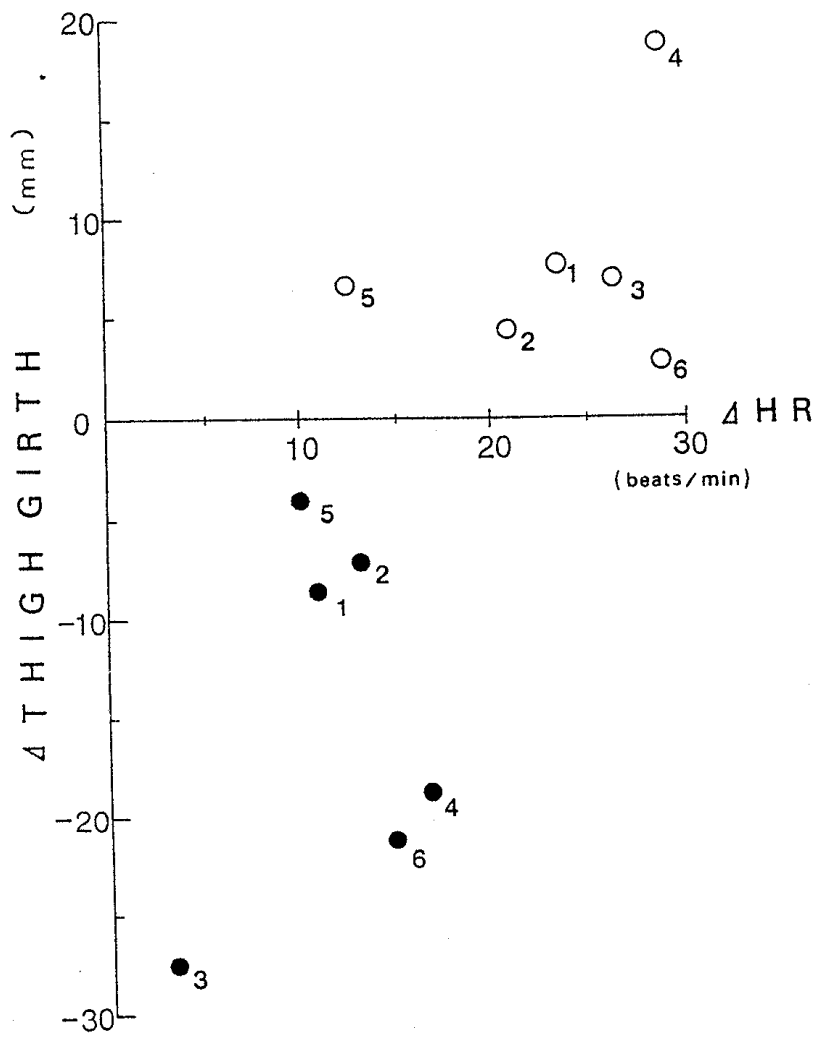

Fig. 4 The relationship between the thigh girth and HR. The plotted data were shown by subtracting the value at the end of supine position from that at the end of standing. : with stockings, $\bigcirc$ : without stockings.

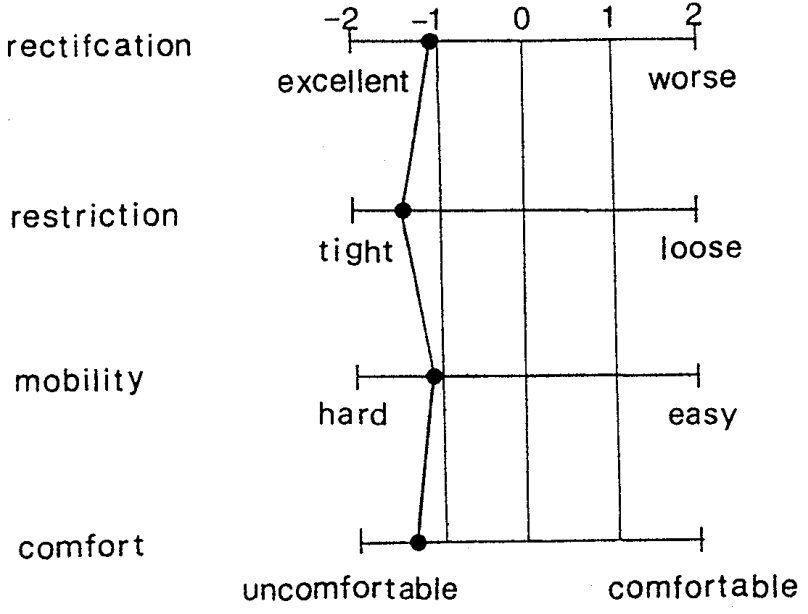

Fig. 5 Subjective evaluation during wearing the compression stockings.

\section{2) EXP. 2}

The authors attempted to estimate the appropriate pressure, which was lower than practical clothing pressure, producing a significantly larger $\dot{Q}$ as compared with control. Although the combinations

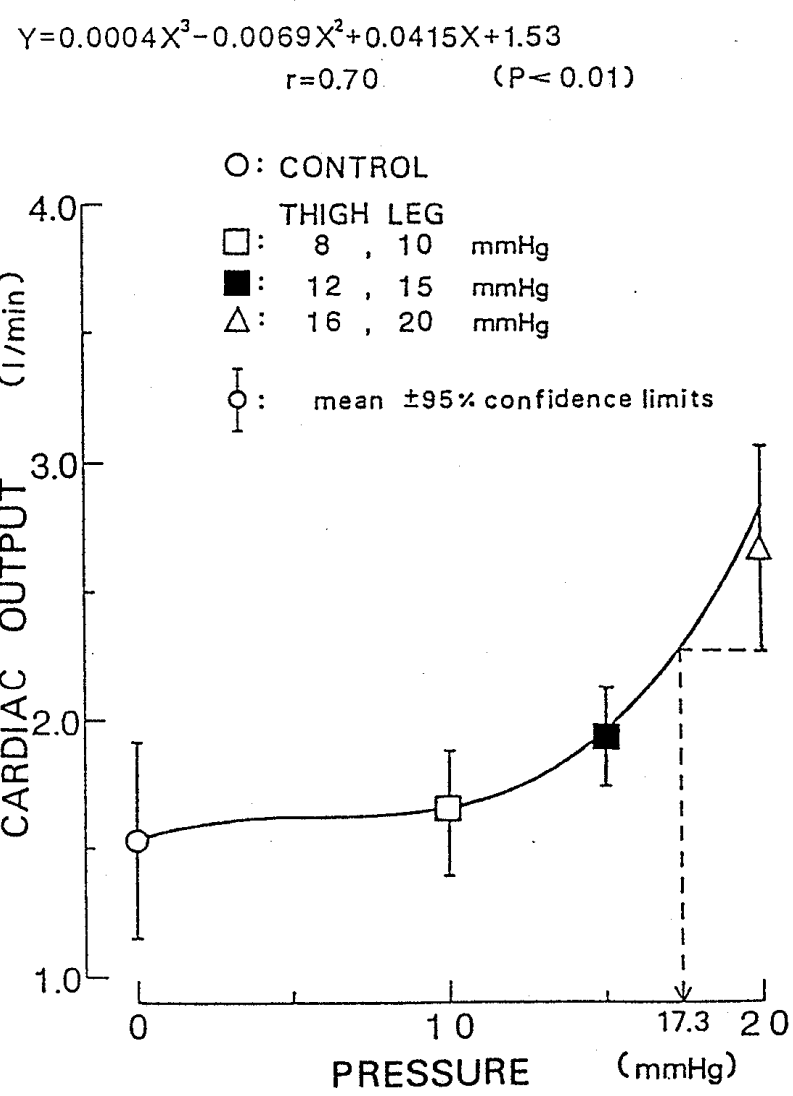

Fig. 6 The relationship between $\dot{Q}$ and the pressure applied to the leg. The estimated pressure increasing $\dot{Q}$ was $17.3 \mathrm{mmHg}$. 


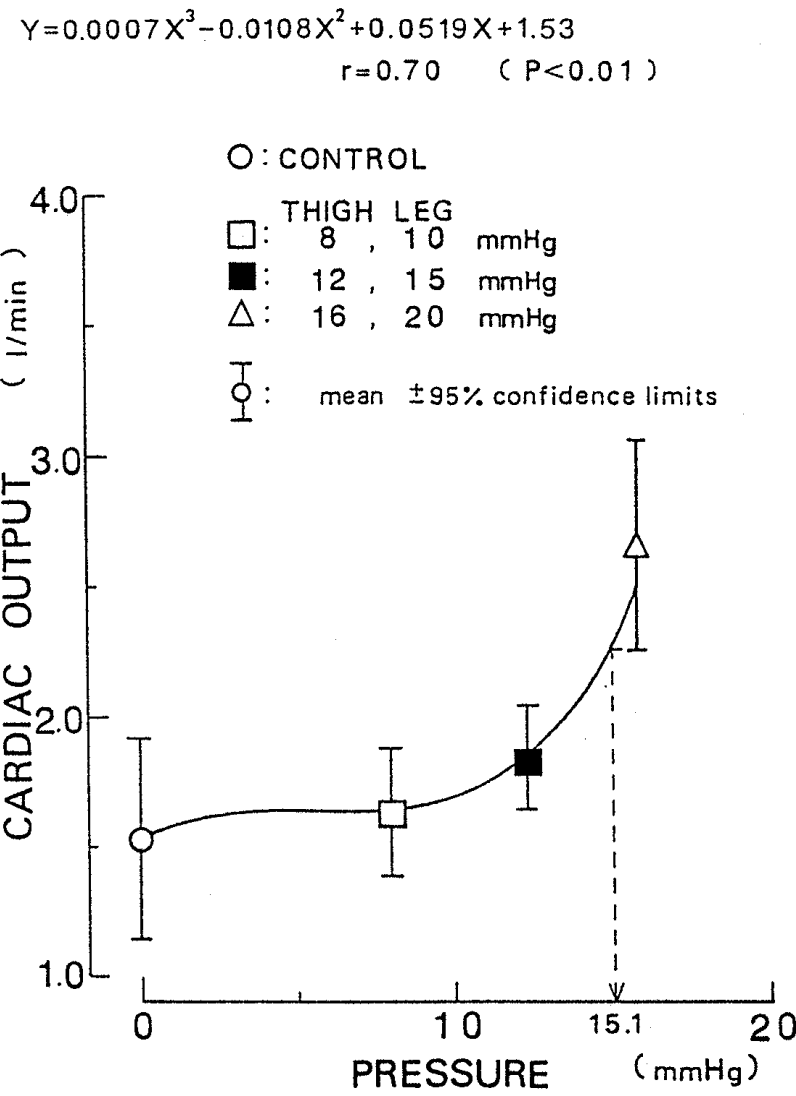

Fig.7 The relationship between $\dot{Q}$ and the pressure applied to the thigh. The estimated pressure increasing $\dot{Q}$ was $15.1 \mathrm{mmHg}$.

of the pressure applied to the leg and thigh were 10 and 8,15 and 12,20 and $16 \mathrm{mmHg}$, the same increase of $\dot{Q}$ and SV and decrease of $\mathrm{HR}$ as those with stockings were observed in that of 20 and $16 \mathrm{mmHg}$. Accordingly, the lower critical pressure for improving venous return existed between 15 and $20 \mathrm{mmHg}$ at leg and between 12 and $16 \mathrm{mmHg}$ at thigh.

Figure 6 shows the relationship between $\dot{Q}$ and the pressure applied to the leg. The higher correlation coefficient was observed at cubic equation $(\mathrm{Y}=$ $0.0004 \mathrm{X}^{3}-0.0069 \mathrm{X}^{2}+0.0415 \mathrm{X}+1.53 ; \quad \mathrm{Y}=\dot{\mathrm{Q}} ; \quad \mathrm{X}=$ pressure). When the value of lower confidence limit of $\dot{Q}(\Delta)$ obtained by an applied pressure of 20 $\mathrm{mmHg}$ was substituted for $\mathrm{Y}, \mathrm{X}$ (i.e. the pressure) was $17.3 \mathrm{mmHg}$. The calculated pressure at thigh in the same manner was $15.1 \mathrm{mmHg}$ (Fig. 7).

\section{DISCUSSION}

The compression stockings used in this study increased $\dot{Q}$ in a prolonged standing position (Fig. 2). This result shows that the venous return with the stockings is larger than that without it. It is useful for people who tend to show a swelling after prolonged standing and sitting. Even for a healthy man in a hot environment where the efficiency of muscle pump decreases immediately due to full of blood in the vein after the pumping, the compression stockings may help to increase the venous return.

However, the subjects complained of discomfort due to the high pressure applied to the skin by wearing the stockings (Fig. 5). It is important to increase the clothing comfort even in compression stockings. The estimated minimum pressure to improve the venous return is $17.3 \mathrm{mmHg}$ at the leg (Fig. 6) and $15.1 \mathrm{mmHg}$ at the thigh (Fig. 7), whereas the practical pressure applied by wearing the stockings was $25 \mathrm{mmHg}$ at the leg and $20 \mathrm{mmHg}$ at the thigh. The difference between the estimated and practical values seems to be small. However, Watanuki and Mihira (1986) reported that the differential limen against the pressure of $20 \mathrm{mmHg}$ applied to the lower extremity ranged from 4 to 4.7 mmHg. Furthermore, they (1987) showed that the subjects complained of "tight" and "fairly tight" when the pressures of 17.5 and $25 \mathrm{mmHg}$ were applied to the lower extremities respectively. Accordingly, if the pressure alters from a practical to an estimated value, then the subjective discomfort may decrease.

On the other hand, the pressurization of the skin may cause some physiological disorders. The increasing order of the pressure between the venous side and arterial side of the capillary may be as follows: vein $<$ interstitial tissue $<$ artery. The pressure applied to the skin by the stockings may increase the interstitial fluid pressure around the capillaries. The increased pressure assists in the transport of excess fluid back into the circulation (vein). However, if this pressure is higher than the pressure on the arterial side of the capillary by arterial disease, the nutrient may not pass from the 
artery into the tissue. In the normal artery, the gradient between pressure in the capillary and that in the tissue might be decreased by the compression. Excess compression may cause the disturbance of nutrient transport. A new critical pressure should be investigated from the aspect of the nutrient transport in the capillary.

Another problem is that the pressure applied to the skin may affect the autonomic nervous system. For example, the sweat rate decreased during wearing the body suit (Tokura et al., 1983) and swim suit (Maruta and Tokura, 1988). Tokura (1988) reported that the salivary gland activity which may be increased by acceleration of autonomic nervous system was decreased by wearing the body suit, one of the compression garments aimed to rectify the body shape. Sugimoto (1991) found an increase of urinary noradrenaline excretion during the wearing of the girdle. It is possible that the pressure may cause the alternation of autonomic nervous system.

Although the authors confirmed the increase of venous return by wearing the compression stockings, more research on for e.g. the relationship between the pressure and the heart rate variability as an index of parasympathetic or sympathetic activity should be investigated for the development of comfortable stockings.

\section{Acknowledgment}

We are grateful to Miss Akiko Odagawa, of Osaka City Univ. and Miss Youko Ikeda, of the Kyoto Laboratory, Gunze Corporation, for their cooperations in the experiments. This study was supported in part by a Grant in Aid for Scientific Research 01304056 (to H. Tokura) from the Ministry of Education, Science, and Culture, Japan, and Gunze Corporation, Kyoto Laboratory, Kyoto, Japan.

\section{REFERENCE}

Brožek, J., F. Grande, J.T. Anderson and Keys, A., 1963: Densitometric analysis of body composi- tion: Revision of some quantitative assumptions. Ann. N.Y. Acad. Sci., 110 : 113-140.

Hagan, R.D., F.J. Diaz and Horvath, S.M., 1978: Plasma volume changes with movement to supine and standing positions. J. Appl. Physiol., 45(3): 414-418.

Katsuura, T., 1979: Effect of posture on cardiac output under different air temperature conditions (in Japanese with English abstract). J. Antrop. Soc. Nippon, 87(2) : 146-152.

Maruta, N. and Tokura, H., 1985 : Effects of skin pressure by swimsuit on local sweat rate, respiratory frequency, heart rate and clothing feeling in sedentary women at ambient temperature of $35{ }^{\circ} \mathrm{C}$. J. Home Econ. Jpn., 39 : 607-611.

Nagamine, S. and Suzuki, S., 1964 : Anthropometry and body composition of Japanese young men and women. Human Biol., 36 : 8-15.

Sugimoto, H., 1991 : Compression of body by clothing. Increase in urinary norepinephrine excretion caused by foundation garments (in Japanese with English abstract). Jpn. J. Hyg., 46(2) : 709-714.

Tokura, H., Komatsu, Y. and Tamura, N., 1983: Effect of skin pressure applied by clothing upon sweating rates in sedentary women. J. Home. Econ. Jpn., 34 : 633-637.

Tokura, H., 1988: Physiological significance of clothing and human health. Proc. Int. Symposium on clothing comfort studies in Mt. Fuji., Jap. Res. Assn. Text. End-Use, 203-222.

Watanuki, S. and Mihira, K., 1986: The effects of pressure in lower extremity on psychological characteristics (in Japanese with English abstract). Ann. Physiol. Anthrop., 5(1) : 13-17.

Watanuki, S. and Mihira, K., 1987 : The change of the pressure sensation and plethysmogram by wearing the pressure suit (in Japanese with English abstract). Ann. Physiol. Anthrop., 6(4): 247 -254 .

(Received September 28, 1993) (Accepted February 18, 1994) 
Shigeki WATANUKI

綿 貫 茂 喜
Faculty of Human Life Science, Osaka City University

3-3-138 Sugimoto, Sumiyoshi-ku, Osaka 558, Japan

于558 大阪市住吉区杉本3-3-138 大阪市立大学生活科学部 